\title{
Perfil de usuários de biblioteca governamental: o caso do Ministério da Saúde
}

Tatiara Paranhos Guimarães

\begin{abstract}
Mestre em Ciência da Informação pela Universidade de Brasília;Coordenadora do Serviço de Referência do Centro de Informação e Pesquisadora da Embaixada dos Estados Unidos.
\end{abstract}

O estudo identificou o perfil dos usuários reais e potenciais da Biblioteca do Ministério da Saúde (MS). Verificou que grande parte dos servidores do MS possui alguma fluência em espanhol, utiliza principalmente a Internet e sites no processo de busca por informações, utiliza a Biblioteca Virtual em Saúde com maior freqüência em relação a outros serviços prestados pela Biblioteca do Ministério e estão satisfeitos com a referida Biblioteca.

Palavras-chave: Estudos de usuários; Perfil de usuários; Biblioteca; Ministério da Saúde.

\section{Profile of government library users: the Federal Health Department case}

This survey aimed to identify the profile of Ministério da Saúde Library users. According to the results, the majority of respondents is somewhat fluent in Spanish, has been using Internet and web sites to gather information, uses the Biblioteca Virtual em Saúde more often when compared to other services and products offered by the Library. Finally, they are very satisfied with the services provided.

Keywords: User survey; User's profile; Library; Federal Health Department.

Recebido em 26.06.2007 Aceito em 01.10.2007 


\section{Introdução}

Percebe-se, neste início de século XXI, uma mudança de enfoque em unidades de informação a respeito do armazenamento de acervos, para a acessibilidade de informações. Nesse atual paradigma, do acesso à informação, o usuário tem desempenhado um papel importante, ocupando posição estratégica e apoiando o desenvolvimento e a oferta de serviços e produtos de informação.

A oferta de produtos e serviços em bibliotecas e em centros de informação e documentação, orientada de acordo com as necessidades e expectativas de seu público-alvo, fornece subsídios para o alcance efetivo da missão dessas unidades, que consiste em selecionar, tratar e disponibilizar informação para seus usuários.

A informação, em especial na área de saúde, vem sofrendo um crescimento exponencial com o desenvolvimento das tecnologias respectivas (TAVARES, 2005). Aliado a esse contexto, o aumento das informações disponibilizadas na $W e b$ vem afetando o comportamento de busca dos usuários, gerando também uma autonomia nesse processo.

As necessidades informacionais dos indivíduos, tanto pessoais como profissionais, têm se acentuado diante do volume de dados ao alcance deles. A utilização de meios de comunicação mais eficientes e baratos, principalmente a da Internet, possibilita a exploração de um volume maior de informação (GIOPATO, 2004). Essa nova realidade destaca ainda mais a função a ser desempenhada por bibliotecários e bibliotecas, que atuam como intermediários no acesso à informação.

Nesse panorama, a Biblioteca do Ministério da Saúde (BMS) percebeu a necessidade de realizar este estudo para identificar o perfil de seus usuários, com o objetivo de melhor atendê-los. Essa necessidade foi indicada no documento que tratou da administração institucional do Ministério da Saúde, o qual apresentava as ações da Secretaria de Assuntos Administrativos (SAA) para os anos de 2005 e 2006. Entre as ações da SAA estabelecidas para esse período, foi recomendada a realização do mapeamento do perfil do usuário da Biblioteca (BRASIL, 2005).

Definir o perfil e as necessidades de informação dos usuários da Biblioteca do Ministério da Saúde constituiu um desafio, considerando que os interesses são diversos e mutáveis. Este estudo pretendeu realizar ainda uma análise do comportamento de busca e uso da informação, centrada nas necessidades dos usuários reais e potenciais da BMS.

É importante ressaltar que a necessidade de informação varia de indivíduo para indivíduo e de grupo para grupo, podendo ser transformada, ou não, em demanda, isto é, na formulação expressa de um desejo de um usuário ou na solicitação de uma informação a uma unidade de informação (NASCIMENTO; WESCHENFELDE, 2002).

Nesse sentido, julgou-se importante analisar o problema individual do usuário, identificando quais informações um indivíduo quer encontrar e como o sistema de informação pode melhor ser planejado para satisfazer essas necessidades. A sua identificação pode resultar no desenvolvimento 
de produtos especializados a serem oferecidos de forma continuada, levando-se em consideração que tanto as preferências individuais como as grupais modificam-se no decorrer do tempo.

Essa postura pró-ativa exige do gestor da unidade de informação uma alta flexibilidade e criatividade na oferta de produtos e serviços, buscando uma interação direta e constante com os usuários. As unidades de informação devem ser gerenciadas de acordo com as necessidades e expectativas dos usuários, maximizando sua eficiência e sua eficácia, abordagem defendida pela filosofia de marketing (AMARAL, 1996).

\section{Estudos de usuários}

Os estudos de usuários podem ser definidos como investigações realizadas com o objetivo de identificar as necessidades de informação dos indivíduos, e se elas estão sendo satisfeitas de maneira adequada (FIGUEIREDO, 1994).

Diversos fatores podem influenciar o comportamento do usuário com relação à informação, tais como: formação básica, treinamento na utilização dos produtos e serviços oferecidos, acessibilidade, condições de trabalho, tempo disponível, posição sócio-cultural, sociabilidade, grau de competição dentro de seu grupo, imagem da informação que cada um tem e experiências anteriores (GUINCHAT; MENOU, 1994).

Para proporcionar a satisfação de uma necessidade de informação, as unidades devem estar aptas a se adaptar às características específicas de cada usuário, decorrentes dos fatores que influenciam 0 seu comportamento e do contexto em que está inserido (FIGUEIREDO, 1999).

Os estudos realizados com o intuito de identificar as necessidades e expectativas de usuários de unidades de informação podem ser realizados de acordo com duas abordagens: a tradicional ou demográfica e a alternativa ou cognitiva.

A abordagem tradicional tem como foco principal o sistema de informação, que inclui o acervo, as bases de dados, os bibliotecários e as relações dos usuários com o próprio sistema; e é direcionada pela ótica dos serviços de informações (DERVIN; NILAN, 1997). A abordagem alternativa busca compreender o que são necessidades de informação, qual o uso da informação e os aspectos que dizem respeito aos usuários, tais como seus sentimentos e percepções. Ou seja, enfoca o problema individual do usuário, identificando o que um indivíduo quer encontrar no sistema de informação, e como este pode melhor ser projetado para atender a essas necessidades (DERVIN; NILAN, 1997).

Esta pesquisa foi orientada segundo a abordagem tradicional, levantando e analisando os aspectos demográficos relacionados com os usuários reais e potenciais da Biblioteca do Ministério da Saúde.

Durante a revisão de literatura, foram encontrados alguns estudos realizados na área de saúde, tais como o de Teixeira (2004), Tavares (2006), Martins (2006) e Lima (2006).

Teixeira (2004) identificou o perfil de usuários de biblioteca de uma indústria farmacêutica. Dentre alguns dos pontos observados estão: um 
grande número de usuários faz consultas ao acervo de livros e solicitam levantamento bibliográfico ao bibliotecário; todos os produtos e serviços oferecidos pela biblioteca são conhecidos e bastante utilizados; a biblioteca tem uma freqüência diária muito baixa, o que reforça a necessidade de elaboração de uma campanha de marketing da biblioteca; as fontes informacionais mais utilizadas são o acervo de livros e de periódicos, as bases de dados, o levantamento bibliográfico e a solicitação de artigos científicos à Bireme; os usuários não fazem uso do Comut; a falta de tempo foi considerada o motivo da não utilização da biblioteca por uma parte dos usuários; e, por fim, a maioria considera a biblioteca eficiente.

A abordagem dos estudos de usuários, como ferramentas de qualidade em serviços de informação na área de saúde, é comentada por Tavares (2006). Esta autora coloca a importância do delineamento do perfil de usuários da informação médica para que estes possam ter suas necessidades de informação satisfeitas de forma eficiente.

O estudo de Lima (2006) identificou as experiências e necessidades dos médicos residentes, matriculados no Programa de Residência Médica da Famema em 2003, quanto ao uso de fontes de informações e bibliotecas, durante a graduação. Verificou-se que: a maioria dos médicos recém-formados adquiriu experiências no uso de bibliotecas com catálogos automatizados durante a graduação; menos da metade dos residentes apontou ter sido capacitada por meio de cursos durante a graduação em Medicina; livros, folhetos, periódicos impressos e a base de dados Medline foram identificadas como as fontes mais usadas pelos residentes, sendo que as buscas em sites gerais na internet apareceram em quarto lugar; outras bases de dados da Bireme, como anais de eventos, CD-ROMs, slides, fitas de videocassete, teses e dissertações, tiveram pouca indicação de uso.

Destacam-se outras pesquisas realizadas com o intuito de identificar o perfil de usuários de centros de informação. O estudo de Cardoso e Ramalho (2006), por exemplo, analisou o processo de busca por informação adotado por professores do curso de Biblioteconomia da Universidade Federal da Paraíba (UFPB). Foi verificado que os canais informacionais utilizados pelos professores são diversos, destacando-se a Internet e a Biblioteca. Entre os recursos e serviços oferecidos pela biblioteca da UFPB, o empréstimo e os periódicos são os mais utilizados, e a avaliação dos professores sobre esses serviços varia entre bom, razoável e deficiente.

Nascimento e Weschenfelde (2006) estudaram as necessidades dos vereadores de Florianópolis e o uso que fazem da informação. Constataram que eles preferem os tipos tradicionais de documentos impressos, mas utilizam a Internet em seu processo de pesquisa.

\section{Ambiente do estudo: Biblioteca do Ministério da Saúde}

A Biblioteca do Ministério da Saúde (BMS) tem por missão prestar serviços de coleta, pesquisa e informação na área de saúde, ciências 
médicas e áreas afins, mantendo intercâmbio com redes de informação nacionais e internacionais.

A BMS, buscando garantir a eqüidade no acesso à informação em saúde, propõe o atendimento a uma comunidade ampla, que pode ser dimensionada pela própria abrangência do Sistema Único de Saúde (SUS) nas esferas governamentais federal, estadual e municipal. Considera-se comunidade usuária do Ministério da Saúde o conjunto de servidores do próprio Ministério e das instituições vinculadas, dos Núcleos Estaduais, e os cidadãos em geral que demandam informação na área de saúde (BRASIL, 2006).

Os principais serviços e produtos oferecidos pela Biblioteca do Ministério da Saúde incluem: Biblioteca Virtual em Saúde (BVS), Serviço de Referência e Empréstimo, Intercâmbio, Localizador de Informação em Saúde, Portal Lis-sp de consulta à Legislação, Pesquisa on-line, Alerta Bibliográfico, Informação para a Saúde (boletim trimestral que divulga os artigos de periódicos do setor Saúde), Alerta Legis (informativo eletrônico bissemanal).

O acervo da Biblioteca é composto por diversos tipos de documentos em diferentes suportes de registro de informação, tais como: livros, folhetos, manuais, dicionários, enciclopédias, dissertações, teses, periódicos, fôlderes, vídeos, CD-Roms/DVDs, disquetes, materiais tridimensionais e realias.

A cobertura temática de atuação da BMS está focada na área de saúde, com maior ênfase na de saúde pública. Outro indicador para a definição da cobertura temática é o conjunto de programas e projetos do Governo nacional que buscam suporte informacional na BMS para a implementação de suas ações (BRASIL, 2006). Além desses temas/assuntos, a Biblioteca pode também cobrir as áreas de apoio aos servidores que atuam no Ministério da Saúde.

\section{A pesquisa}

Partindo dos objetivos propostos, procurou-se responder às seguintes questões: Qual o perfil dos usuários reais e potenciais da Biblioteca do Ministério da Saúde? Quais são suas necessidades potenciais e preferências em termos de características e atributos de produtos e serviços de informação? Como vêm utilizando os recursos da Biblioteca? Qual o grau de satisfação dos usuários quanto a serviços e recursos disponibilizados?

Para o desenvolvimento do estudo, optou-se pelo questionário como mecanismo principal de coleta de dados (ver Apêndice II). Outros métodos complementares, como a análise documental e a observação direta (ver Apêndice I), foram utilizados a fim de aprofundar a compreensão dos dados obtidos. Dessa forma, a coleta foi realizada em três etapas:

1-Análise do Regimento Interno do MS, das estatísticas do setor de referência, do Planejamento Estratégico da Secretaria de Assuntos Administrativos (SAA) e da Política de Desenvolvimento de Coleções 
da Biblioteca, com o objetivo de identificar contextos situacionais em que os usuários estão inseridos e nos quais os serviços e produtos são oferecidos;

2-Observação direta, que consistiu em visitas à Biblioteca do Ministério da Saúde nos dias 4 e 11 de setembro de 2006, entre as $10 \mathrm{~h}$ e $12 \mathrm{~h}$ e entre as $15 \mathrm{~h}$ e $17 \mathrm{~h}$, com o intuito de analisar os hábitos dos seus usuários. Visto que a pesquisa pretendeu alcançar os servidores do Ministério, optou-se por realizar a observação direta durante o horário de expediente;

3-Formulário eletrônico com os itens do questionário, enviado por email para o universo dos 4.000 servidores do Ministério lotados no Distrito Federal (DF). Nessa linha, trata-se de uma pesquisa censitária.

A análise dos dados coletados por meio dos questionários foi realizada utilizando-se o software Excel, com a elaboração de gráficos e tabelas. A análise dos dados coletados por meio das observações diretas foi feita através de agrupamento, codificação e classificação dos atributos relacionados aos objetivos desta pesquisa.

Com relação aos usuários, pode-se dizer que a BMS possui cinco segmentos: os servidores do Ministério da Saúde, os cidadãos em geral, estudantes, gestores e pesquisadores. Pretendeu-se alcançar, em um primeiro momento, de forma censitária, o segmento dos servidores do MS, visto que este é o público-alvo da Biblioteca. Dessa forma, a população deste estudo foi constituída por 4.000 servidores do Ministério da Saúde lotados no DF.

\section{Resultados}

\subsection{Resultados da observação}

Com um formulário de apoio, foram observados hábitos e comportamentos dos usuários no interior da Biblioteca relativos ao uso do espaço, serviços e produtos, sem que eles percebessem que estavam sendo examinados. A observação direta durou um total de oito horas.

Sessenta usuários compareceram à Biblioteca nesse intervalo de tempo, uma média de sete usuários por hora. Pôde-se aferir que grande parte deles tinha idade aproximada entre 31 e 40 anos (54\%). Uma minoria (23\%) tinha entre 21 e 30 anos, $15 \%$ tinham entre 41 e 50 anos e apenas $8 \%$ tinham entre 15 e 20 anos. Com relação ao gênero, observou-se equilíbrio entre a proporção de indivíduos do sexo masculino $(53 \%)$ e feminino (47\%).

Foi possível observar também que grande parte dos usuários permaneceu na Biblioteca por um período de dez a 30 minutos $(45 \%)$. Outros $23 \%$ até dez minutos, $20 \%$ entre 30 minutos e uma hora; e apenas $12 \%$ permaneceram por mais de uma hora. Esses dados sugerem que a maioria permanece pouco tempo na Biblioteca. Uma das razões 
para isso pode ser o fato de a unidade não funcionar em horários diferentes daquele do expediente do Ministério, não oferecendo, portanto, facilidades de acesso a usuários que pretendam utilizar seus serviços antes ou após o horário normal de trabalho.

Com relação às atividades desenvolvidas, foi percebido que aproximadamente $34 \%$ dos usuários consultaram as bibliotecárias ou devolveram livros no balcão de referência, 30\% utilizaram o terminal para pesquisas na Internet e $36 \%$ foram à Biblioteca para realizar leitura ou estudo individual. As atividades realizadas pelos usuários durante sua permanência na Biblioteca foram distribuídas de uma forma igualitária, sendo que aproximadamente um terço dos usuários consultou a Internet, um terço utilizou o serviço de referência e empréstimo e um terço fez uso do espaço para leitura e estudo. Nota-se que os terminais para consulta na Internet constituem um recurso efetivo para atrair usuários. No entanto, a Biblioteca deveria adotar outras medidas para atrair e manter os seus usuários por mais tempo em seu espaço para estudo e leitura, como, por exemplo, a ampliação do horário de funcionamento.

Durante a observação, notou-se que os usuários que ficaram por mais de uma hora na Biblioteca utilizaram seu tempo pesquisando na Internet ou estudando individualmente. Os indivíduos que permaneceram por menos de dez minutos consultaram as bibliotecárias no balcão de referência. Esses dados apenas confirmam que as atividades relacionadas a pesquisas na Internet e leitura são as que demandam mais tempo. Além disso, pode-se inferir que as questões de referência relacionam-se com temas factuais, não demandando da Biblioteca buscas mais aprofundadas. Ainda, como os usuários observados são, regra geral, funcionários públicos não-acadêmicos, suas consultas à Biblioteca podem estar relacionadas com necessidades de informações específicas.

\subsection{Resultados do questionário}

Dos 4.000 servidores lotados no DF, universo para o qual foram enviados os questionários, 336 responderam à pesquisa, o que corresponde a um índice de 8,4\%. Desses, 192 relataram ter utilizado a Biblioteca do MS e os 144 restantes informaram nunca terem usado os serviços e produtos oferecidos. Com base nesses dados, observa-se que quase a metade dos respondentes não utiliza a Biblioteca do MS. Considerando tratar-se de pesquisa censitária, não é possível estimar a amostra representativa da população. Os perfis desses respondentes serão discutidos adiante, considerando-se dados demográficos e hábitos dos usuários reais e potenciais, como também avaliação dos serviços e produtos oferecidos pela Biblioteca do MS.

No tocante aos dados demográficos, observou-se que a quase totalidade dos respondentes, 97\%, encontrava-se na faixa etária entre 21 e 60 anos (26\% entre 21 e 30 anos, 27\% entre 31 e 40 anos, 27\% entre 41 e 50 anos e $17 \%$ entre 51 e 60 anos). O pequeno percentual de indivíduos com menos de 21 e mais de 60 anos deve-se ao fato de que esses extremos não correspondem ao perfil de idade de servidores 
públicos. Os menores de 21 geralmente ainda não ingressaram no serviço público e os maiores de 60 já saíram dele. Com relação ao gênero, 70\% dos respondentes eram do sexo feminino.

A maioria dos servidores que responderam ao questionário (82\%) tem nível superior, sendo que, destes, $36 \%$ são graduados, $33 \%$ possuem curso de especialização, $13 \%$ são mestres, $2 \%$ têm doutorado e $1 \%$ pósdoutorado. Apenas $15 \%$ freqüentaram somente o segundo grau. Percebese que a maioria possui curso de graduação e que, em princípio, são usuários que demandam fontes bibliográficas mais técnicas e especializadas, a fim de subsidiar suas atividades profissionais no Ministério.

A maioria dos respondentes (89\%) está lotada no Distrito Federal, visto que o questionário foi enviado apenas para o e-mail desses servidores. Alguns servidores de outras unidades da Federação (11\%) também responderam à pesquisa, o que pode ter ocorrido devido ao reencaminhamento do questionário a outros servidores lotados fora do DF, sem que tal iniciativa tivesse sido solicitada pela pesquisa. Grande parte dos respondentes (33\%) está lotada na Secretaria Executiva (SE) do Ministério.

Outro aspecto verificado durante a pesquisa foi o dos hábitos dos usuários reais e potenciais da Biblioteca do MS. No que diz respeito à compreensão de outros idiomas, nota-se, por meio do Gráfico 1 , que a maioria (68\%) não lê em francês e que $57 \%$ ou lêem espanhol razoavelmente ou são fluentes na língua. Outro dado a ser destacado é que quase metade dos respondentes (47\%) lê inglês razoavelmente ou é fluente nesta língua. Esses dados são declaratórios e, nessa condição, pode-se inferir que as duas línguas sobre as quais metade dos respondentes informou possuir domínio razoável são aquelas mais difundidas na sociedade brasileira. Isso implica que a Biblioteca pode ampliar o seu acervo, incorporando fontes de informação especializadas em espanhol e em inglês, permitindo que todos tenham acesso a conteúdos internacionais e mais atualizados. 


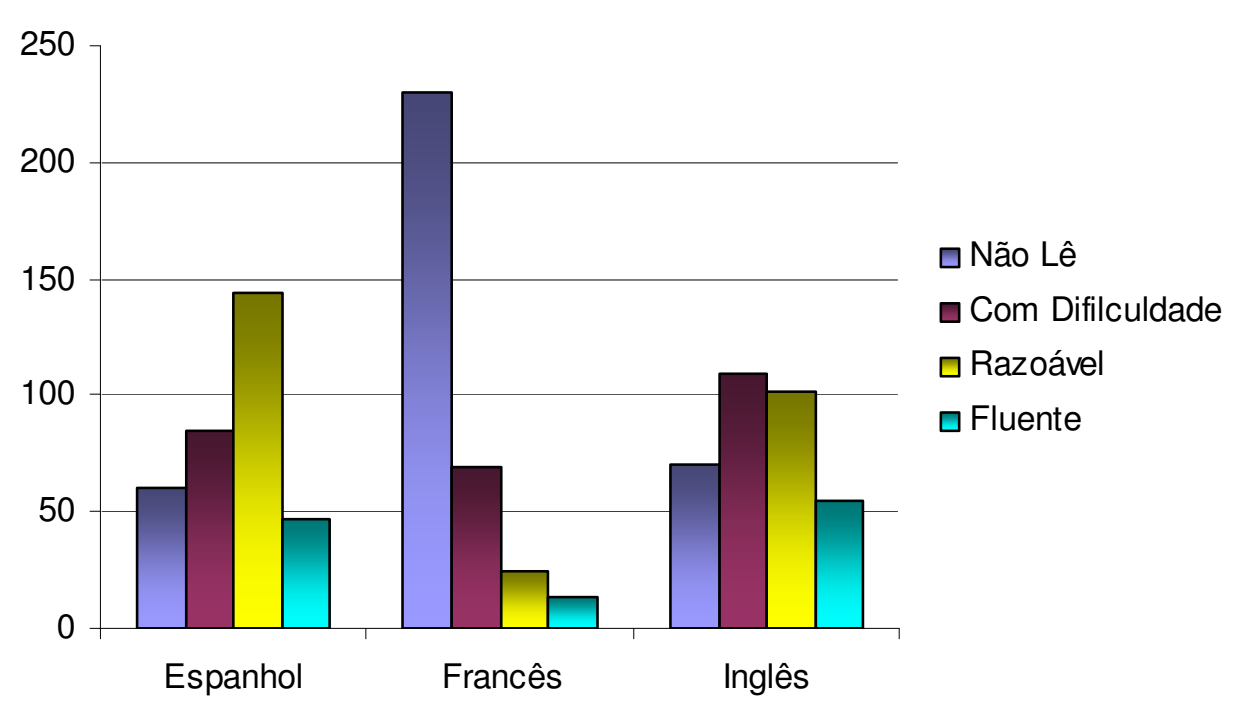

GRÁFICO 1 - Fluência em outros idiomas.

FONTE - Dados da pesquisa.

Pode-se destacar, mediante os dados do Gráfico 2, que o meio mais utilizado pelos servidores do Ministério da Saúde para obter informações é a Internet (82\%). Apenas um servidor relatou não utilizar esse meio e uma minoria de servidores (18\%) o utiliza pouco ou medianamente. Em segundo lugar, os servidores utilizam conversas com colegas e familiares, sendo que $76 \%$ utilizam bastante ou medianamente esse meio. Os dados também mostram que as livrarias são pouco procuradas nesse processo de obtenção de informação pelos servidores do MS. Pode-se perceber ainda que a metade utiliza outros meios (biblioteca particular, outras bibliotecas, TV, rádio e jornal) e metade não o faz. A indicação da Internet como um dos meios mais utilizados para a obtenção de informação também foi observada nos estudos de Cardoso e Ramalho (2006) e de Nascimento e Weschenfelde (2006). Isso se deve ao fato de que a Internet se tornou um meio de comunicação e informação eficiente e barato, o que possibilita a exploração de um maior volume de informação (GIOPATO, 2004, p. 32). O fato de uma grande parte dos respondentes também ter mencionado conversas com colegas e familiares como um dos meios mais freqüentes para obter informação ressalta a constatação óbvia de que usuários utilizam fontes de mais fácil acesso em sua busca por informações pontuais, em contraponto com a pouca utilização de bibliotecas, onde se espera que o usuário realize pesquisas mais aprofundadas. 


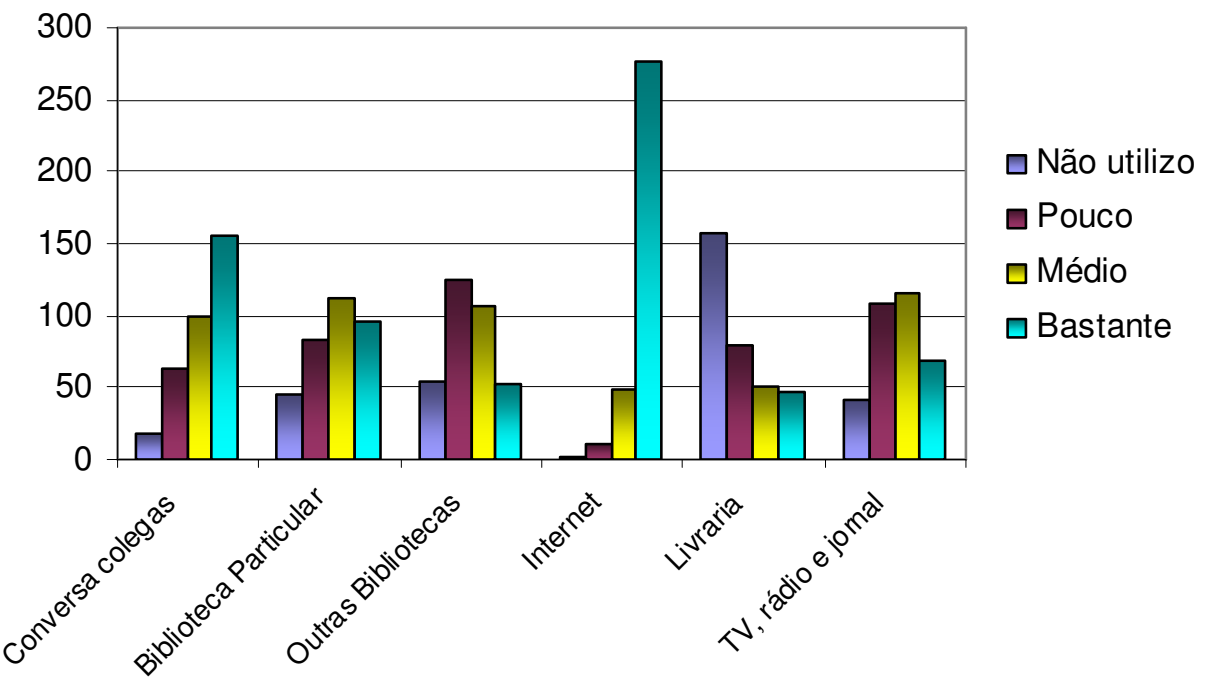

GRÁFICO 2 - Meios mais utilizados para obter informações.

FONTE - Dados da pesquisa.

Quanto aos materiais e fontes mais utilizados para obtenção de informação, percebe-se, no Gráfico 3, que os sites da Internet são bastante utilizados (81\%). Somando-se as opções 'utilizo bastante' e 'utilizo medianamente', o livro aparece em segundo lugar ( $84 \%)$, seguido de documentos técnicos e manuais $(63 \%)$ e de dicionários e enciclopédias (61\%). Mais da metade dos respondentes não utiliza ou utiliza pouco materiais especiais (fôlderes, vídeos e CDS), atlas e mapas, trabalhos acadêmicos (dissertações, teses e monografias). Percebe-se, mais uma vez, que os recursos eletrônicos, tais como os sites da Internet, foram citados como o material mais utilizado para a obtenção de informação. A natureza das atividades profissionais desenvolvidas pelos respondentes deve ser a razão de uma maior utilização de livros, documentos técnicos, manuais, dicionários e enciclopédias. Materiais multimídia (vídeos e CDs), acadêmicos (teses, dissertações e monografias), promocionais (fôlderes) e iconográficos (mapas e atlas), por não serem considerados fontes técnicas, estão sendo pouco consultados. 


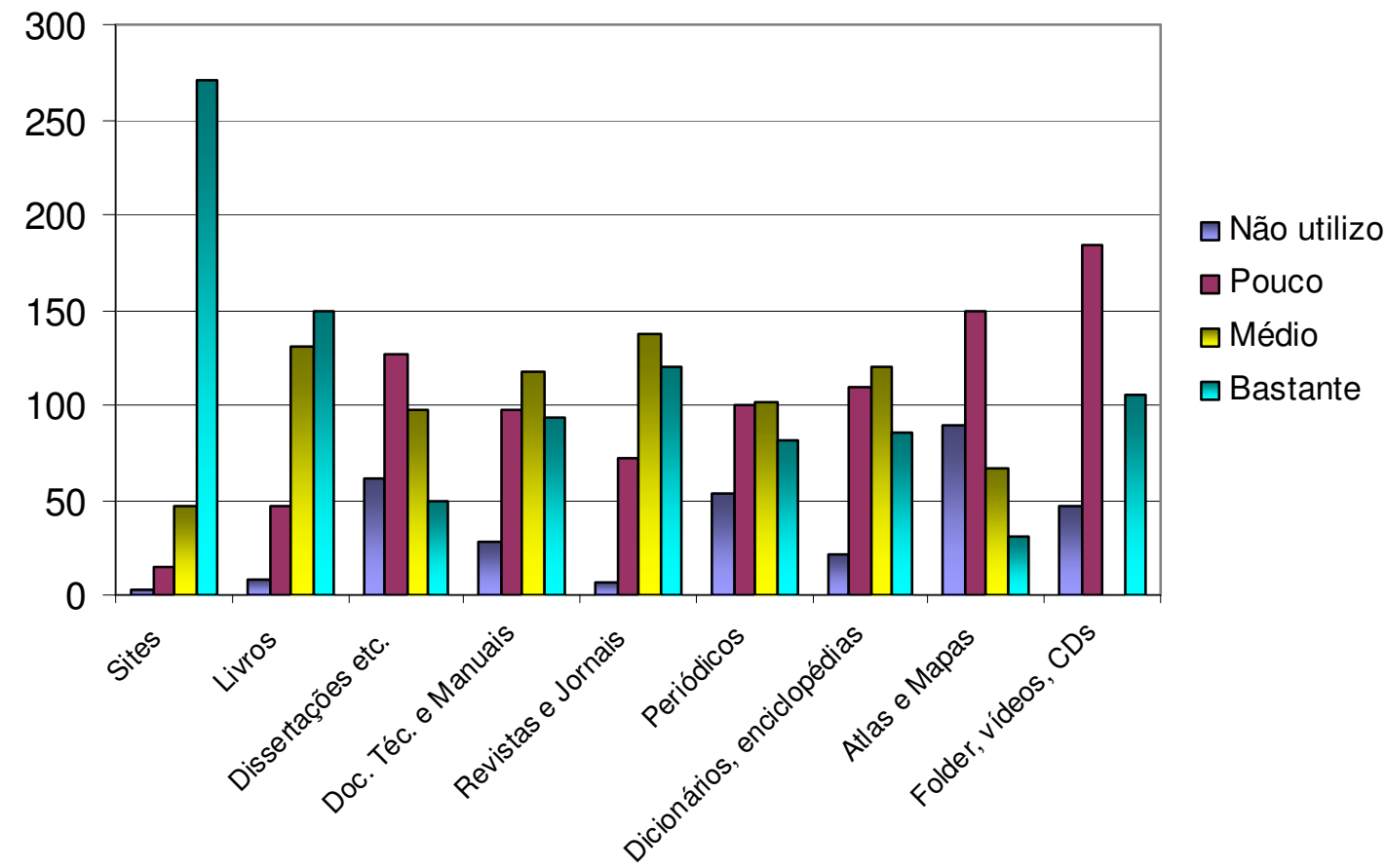

GRÁFICO 3 - Materiais mais utilizados para obter informações.

FONTE - Dados da pesquisa.

O terceiro aspecto estudado foi o uso e a avaliação dos serviços e produtos oferecidos pela Biblioteca do MS por parte apenas dos 192 respondentes que informaram utilizar a Biblioteca, classificados, nesta pesquisa, como usuários reais.

O Gráfico 4 demonstra que a Biblioteca Virtual em Saúde (BVS) é o serviço mais utilizado pelos servidores $(75 \%)$. Outros serviços como a cópia de material (57\%), a pesquisa bibliográfica por artigos (52\%), a orientação do balcão de referência $(51 \%)$, o empréstimo de material $(49 \%)$ e o espaço para leitura (49\%) obtiveram pouca indicação de uso. Os serviços menos conhecidos são o catálogo da biblioteca (36\%), seguido do Comut (32\%) e das bases de dados (31\%). Os terminais para consulta na Internet são conhecidos, mas não são utilizados por $44 \%$ dos usuários. Esses dados confirmam, mais uma vez, resultados descritos na literatura, já comentados neste artigo, segundo os quais os recursos online, a exemplo da BVS, são bastante utilizados na recuperação da informação. Outros serviços, como cópia, pesquisa bibliográfica, empréstimo e leitura, apesar de serem utilizados por mais da metade dos respondentes, ainda apresentam um baixo índice de uso, o que ressalta a necessidade de uma maior divulgação dos recursos bibliográficos da Biblioteca. O Comut e as bases de dados constituem recursos pouco divulgados para os usuários em geral, sendo de domínio maior de bibliotecários e profissionais da informação; o que deve ser razão principal do desconhecimento desses serviços por parte dos respondentes. 


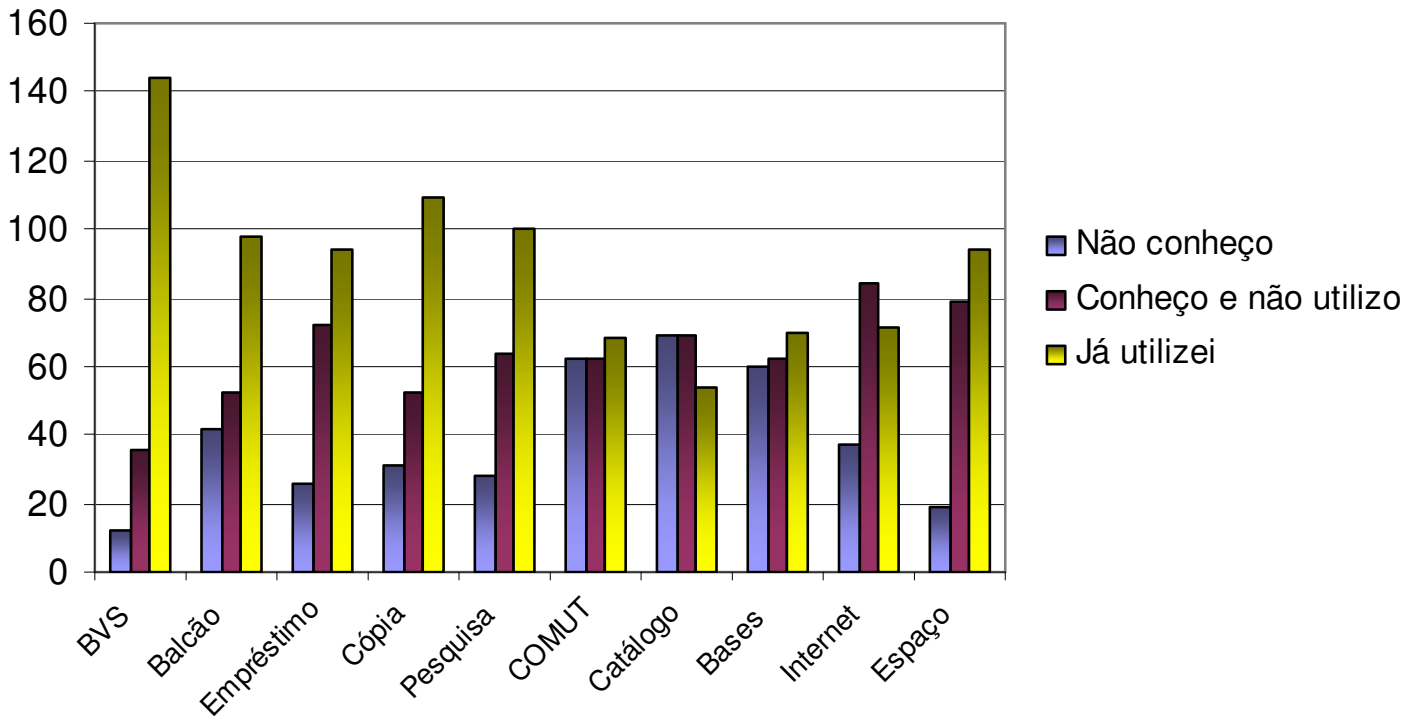

GRÁFICO 4 - Utilização dos serviços da Biblioteca do MS.

FONTE - Dados da pesquisa.

Quanto à avaliação dos serviços oferecidos pela biblioteca pesquisada, $87 \%$ dos respondentes afirmaram que o serviço de referência é bom ou muito bom (ver Gráfico 5). O ambiente (78\%), a Biblioteca Virtual em Saúde - BVS (75\%), o horário de funcionamento (65\%), o empréstimo (62\%), as cópias (59\%) e a coleção (57\%) também receberam avaliação positiva. Um índice alto de usuários (51\%) afirmou não saber avaliar o Comut e $49 \%$ não souberam avaliar ou avaliaram a divulgação como ruim. O fato do serviço de referência, o ambiente da Biblioteca e o empréstimo serem os recursos mais visíveis da Biblioteca pode ser a razão desses recursos receberem avaliação positiva. Por serem os responsáveis pela imagem da Biblioteca, têm merecido destaque e são disponibilizados de uma forma mais adequada por parte das Bibliotecas. A BVS, como serviço mais utilizado pelos respondentes, também recebeu uma avaliação positiva, o que confirma que os recursos mais visíveis são mais bem avaliados. As respostas demonstram ainda que grande parte dos respondentes está satisfeita com o horário de funcionamento da Biblioteca, apesar de este coincidir com o horário de expediente do Ministério, não permitindo que os servidores façam uso dos recursos in loco, em um intervalo maior de tempo. Com relação à avaliação do Comut, os dados confirmam que esse serviço é pouco conhecido pelos usuários, ensejando a necessidade de maior divulgação de serviços da biblioteca. 


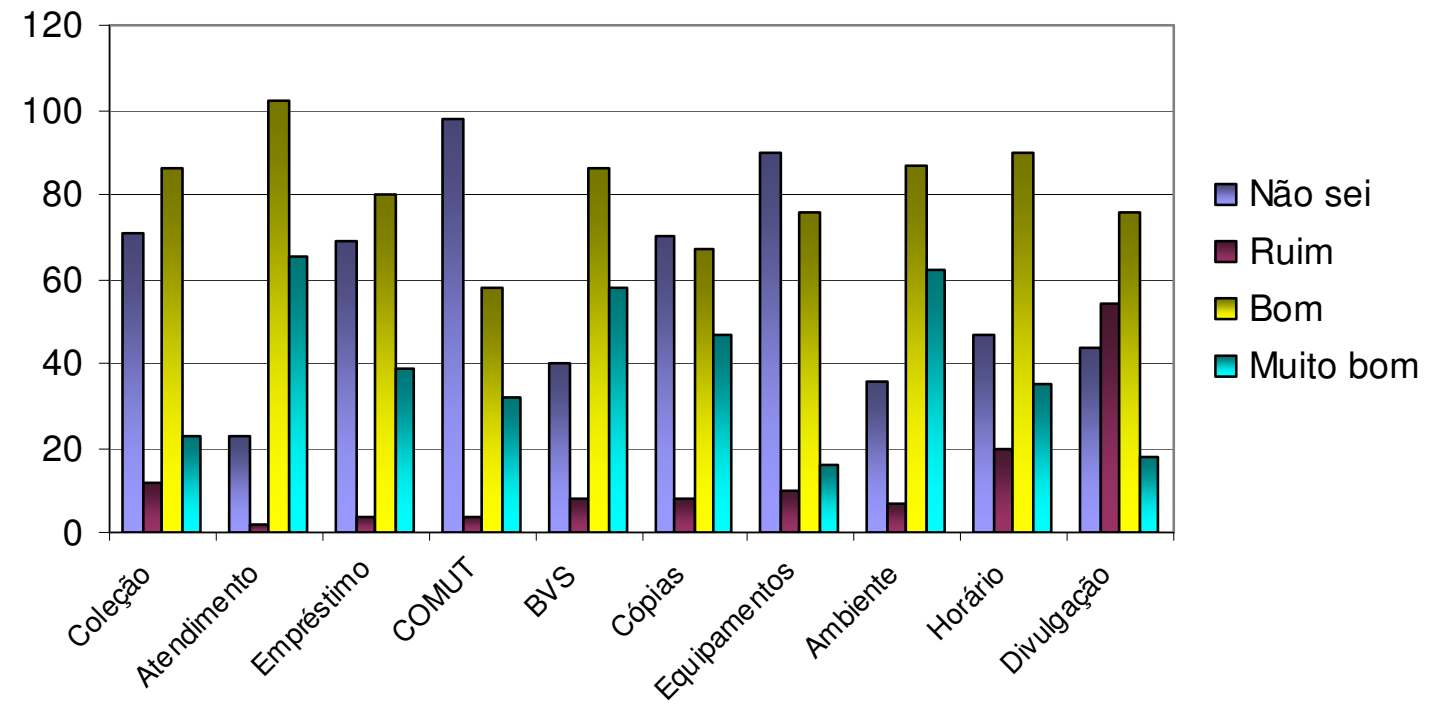

GRÁFICO 5 - Avaliação dos serviços oferecidos pela Biblioteca do MS. FONTE - Dados da pesquisa.

Dos 336 respondentes, 73 deram alguma sugestão, fizeram comentário ou elogio sobre os serviços e produtos oferecidos pela Biblioteca. São eles:

a) 25 comentaram sobre a necessidade de se divulgar mais o que é oferecido pela Biblioteca, visto que alguns ainda não conhecem seus serviços e produtos. Algumas sugestões dos servidores são: a utilização de informativos e fôlderes, o desenvolvimento de campanhas de conscientização, maior uso do e-mail como canal para promover a biblioteca, distribuição de boletim de novas aquisições, dentre outras.

b) 12 dos servidores que já utilizaram a Biblioteca elogiaram os serviços e produtos oferecidos, em especial o atendimento.

c) 12 sugeriram: a ampliação das áreas de conhecimento cobertas, abrangendo não apenas temas relacionados com Saúde; o acesso direto às estantes e a atualização das portarias disponíveis.

d)07 comentaram sobre a necessidade de simplificação e/ou facilitação do processo de pesquisa e busca da BVS. Alguns respondentes o avaliaram como confuso e complexo, impedindo que itens e assuntos de que necessitam sejam recuperados com eficiência.

e)05 indicaram a necessidade de agilização e automação na solicitação e entrega de artigos. Os respondentes sugeriram a utilização do e-mail nesse processo de disponibilização de artigos e a assinatura do Portal Capes de periódicos.

f)06 relataram a necessidade de se estender o horário de funcionamento da Biblioteca, visto que, durante o expediente do Ministério, os servidores não dispõem de tempo para utilizar os serviços e produtos oferecidos. 
g)Outros 05 parabenizaram a iniciativa da Biblioteca de realizar esta pesquisa com o intuito de estabelecer um elo maior com seus usuários.

\section{Conclusões e recomendações}

De uma forma geral, os resultados obtidos mostram que grande parte dos respondentes possui alguma fluência em espanhol; utilizam principalmente a Internet e sites no processo de busca por informações de seu interesse; utilizam a Biblioteca Virtual em Saúde com maior freqüência em comparação com outros serviços prestados pela Biblioteca do Ministério da Saúde; estão satisfeitos com a Biblioteca, em especial com o atendimento prestado pelo balcão de referência.

Um dos aspectos que merecem destaque é o fato de os resultados da pesquisa demonstrarem que os servidores do MS vêm demandando a prestação de serviços e produtos em linha, a fim de tornar a disseminação da informação mais ágil. Isso pôde ser comprovado pelo alto índice de respondentes que relataram utilizar a Internet, os sites e a Biblioteca Virtual em Saúde para a obtenção de informações de seu interesse.

A aplicação das novas tecnologias de informação e comunicação em bibliotecas pressupõe a diminuição da participação da biblioteca tradicional e a diminuição de consultas in loco por parte de usuários. Seria interessante que a biblioteca pesquisada se adequasse a essa nova realidade e disponibilizasse fontes e serviços de informação por meio eletrônico, alcançando, desse modo, usuários remotos. Nesse sentido, a Biblioteca do Ministério da Saúde poderia adotar estratégias e ações para atender a essa demanda, automatizando o seu acervo e processos e disponibilizando, cada vez mais, seus serviços e produtos on-line, em especial o atendimento às consultas e pedidos por artigos.

Foi identificada, também, a necessidade de se desenvolver uma maior divulgação sobre o que a Biblioteca pode oferecer a seu público. Os resultados obtidos mostram o grande interesse dos respondentes em receber, por e-mail, informativos sobre a biblioteca, para mantê-los atualizados e informados sobre os recursos disponíveis. A promoção de serviços e produtos da Biblioteca poderia ser realizada por meio de distintas atividades promocionais, tais como relações públicas, merchandising, publicidade, propaganda, incentivos, e aplicada por meio de instrumentos como site institucional, fôlderes, cartazes, brindes etc.

Para tanto, julga-se necessário o desenvolvimento de um plano de marketing da Biblioteca, integrado ao planejamento estratégico da Coordenação-Geral de Documentação e Informação do Ministério da Saúde. Um outro estudo será necessário para desenvolver, na Biblioteca, uma filosofia administrativa voltada para o mercado.

Visto que a maioria dos respondentes relatou ter interesse em receber informativos em formato eletrônico sobre a Biblioteca, a identificação dos temas de interesse dos respondentes poderá possibilitar a criação de um sistema contendo dados e informações sobre seus usuários e o desenvolvimento do serviço de disseminação seletiva da 
informação. A respeito desse serviço, Souto (2006) acredita que a DSI é um meio de garantir que os usuários recebam informações relevantes e atualizadas.

Considera-se que os resultados desta pesquisa trazem insumos significativos para que a Biblioteca possa conhecer melhor o público a ser atingido e aperfeiçoar a prestação de seus serviços e produtos.

Sugere-se que pesquisas como esta sejam realizadas periodicamente e que outros tipos de usuários possam ser contemplados, tais como pesquisadores, estudantes e cidadãos em geral. Dessa forma, a Biblioteca poderia mapear melhor o ambiente em que deverá oferecer seus serviços e produtos.

$O$ interesse em realizar este estudo indica uma mudança de comportamento por parte da Biblioteca do Ministério da Saúde, que, ao procurar identificar necessidades de seus usuários reais e potenciais, atua de forma pró-ativa no que diz respeito à satisfação das reais expectativas de seu público. Essa estratégia pode acarretar diversas vantagens, tais como a antecipação no atendimento e na oferta de serviços e produtos adequados ao público a ser atendido pela Biblioteca, com base nos dados obtidos durante esta pesquisa.

\section{Referências}

AMARAL, S. A. do. Marketing e desafio profissional em unidades de informação. Ciência da Informação, Brasília, v. 25, n. 3, 1996. Disponível em: $<$ http://www.ibict.br/cienciadainformacao/include/getdoc.php?id=831\&article $=49$ 3\&mode=pdf $>$ Acesso em: 15 out. 2006.

BRASIL. Ministério da Saúde. Administração Institucional do Ministério da Saúde. Brasília: Ministério da Saúde, 2005. 26p. Disponível em: <http://dtr2001.saude.gov.br/editora/produtos/impressos/folheto/06 0064 FL.pdf> Acesso em: 21 jul. 2006.

- Ministério da Saúde. Política de Desenvolvimento de Coleções da Biblioteca do Ministério da Saúde. Brasília: Ministério da Saúde, 2006. 35p.

CARDOSO, M. de L.; RAMALHO, F. A. Buscas de informação para satisfação de necessidades: um estudo com professores do curso de biblioteconomia - CCSA/UFPB. Biblionline, v. 2, n.1, 2006. Disponível em: $<$ http://periodicos.ufpb.br/ojs2/index.php/biblio/article/viewFile/595/433> Acesso em: 15 out. 2006.

DERVIN, B.; NILAN, M. Workshop design de bibliotecas virtuais centrado nousuário: a abordagem do sense-making para estudo de necessidades e comportamento de busca e uso das informações. São Paulo: USP, 1997.

FIGUEIREDO, N. M. Estudo de uso e usuários da informação. Brasília: IBICT, 1994.

- Paradigmas modernos da ciência da informação: usuários, coleções, referência e informação. São Paulo: Polis, 1999. 
GIOPATO, W. F. Necessidades de informações gerenciais dos usuários do sistema de serviço militar do Exército brasileiro: uma abordagem centrada no usuário. 89 f. Dissertação (Programa de Pós-Graduação em Ciência da Informação) Universidade de Brasília. 2004.

GUINCHAT,C.; MENOU, M. Introdução geral às ciências e técnicas da informação e documentação. 2. ed. corr. e aum. Brasília: IBICT, 1994. $540 \mathrm{p}$.

LIMA, H. M. da C. Experiências em Buscas de Informações por Residentes de Medicina. Revista Brasileira de Educação Médica, Rio de Janeiro, v. 29, n. 1 , jan./abr. 2006. Disponível em: <http://www.abemeducmed.org.br/rbem/pdf/volume 29 1/experiencias buscas.pdf $>$ Acesso em: 15 out. 2006.

MARTINS, M. de F. M. Uso do portal capes na área biomédica: uma abordagem qualitativa. In: CONFERÊNCIA IBEROAMERICANA DE PUBLICAÇÕES ELETRÔNICAS NO CONTEXTO DA COMUNICAÇÃO CIENTÍFICA,1, 2006, Brasília, D.F, Anais... Brasília: Universidade de Brasília, 2006.2 Disponível em: <http://portal.cid.unb.br/CIPECCbr/viewpaper.php?id=6> Acesso em: 15 out. 2006.

NASCIMENTO, M. de J.; WESCHENFELDER, S. Necessidade de informação dos vereadores de Florianópolis: estudo de usuário. Informação \& Sociedade: estudos, João Pessoa, v. 12, n. 1, p. 321-343, 2002. Disponível em: <http://www.ies.ufpb.br/ojs2/index.php/ies/article/view/161/155> Acesso em: 20 jul. 2006.

SOUTO, L. F. Disseminação seletiva de informações: discussão de modelos eletrônicos. Encontros Bibli: revista eletrônica de biblioteconomia e ciência da informação, Florianópolis, n. esp., 10 sem. 2006. Disponível em: $<$ http://www.encontros-bibli.ufsc.br/bibesp/esp 03/5 GT3 souto.pdf> Acesso em: 15 out. 2006.

TAVARES, P. C. Premissas para um enfoque abrangente e eficiente em estudos de usuários. In: CONGRESSO MUNDIAL DE INFORMAÇÃO EM SAÚDE E BIBLIOTECAS, 9, 2005, Salvador. Anais... Salvador, 2005. Disponível

em: < www.icml9.org/program/track10/public/documents/Patricia\%20Costa\%20Tavar es-152704.doc >. Acesso em: 15 out. 2006.

TEIXEIRA, R. da S. Estudo de usuários na biblioteca de um laboratório farmacêutico: relato de experiência. Perspectivas em Ciência da Informação, Belo Horizonte, v.9 n.2, p. 208-217, jul./dez. 2004. Disponível em: <http://www.eci.ufmg.br/pcionline/viewarticle.php?id=78> Acesso em: 15 out. 2006.

\section{Agradecimentos}

Agradeço à equipe da Biblioteca do Ministério da Saúde e da Coordenação-Geral de Documentação e Informação, em especial a Márcio 
Fernandes Cunha e a Hilton Mendes Sobrinho, que acompanharam e me apoiaram no desenvolvimento desta pesquisa

\section{Apêndice I - Formulário utilizado para observação}

\section{Usuário $n$.}

Data:

Horário de entrada:

Horário de saída:

Idade aproximada:

$\square \quad 15$ a 20 anos

$\square \quad 41$ a 50 anos
$\square \quad 51$ a 60 anos
$\square \quad$ Masculino

Observações: 


\section{Apêndice II - Questionário aplicado aos servidores do MS}

1. Idade:

15 a 20 anos

20 a 30 anos

31 a 40 anos
41 a 50 anos

51 a 60 anos

Mais de 60 anos

\section{Sexo:}

Feminino

Masculino

3. Nível de escolaridade. Favor selecionar apenas uma opção

Ensino fundamental (antigo $1^{\circ}$ grau)

Mestrado

Ensino médio (antigo $2^{\circ}$ grau)

Doutorado

Nível superior (graduação)

Pós-doutorado

Especialização ou MBA

\section{Em qual Estado você reside?}

5. Em que setor do Ministério da Saúde você está lotado?

Favor selecionar apenas uma opção

Gabinete do Ministro

Consultoria Jurídica

Conselho Nacional de Saúde

Conselho de Saúde Suplementar

Departamento Nacional de Auditoria do SUS

$\square$ Secretaria Executiva

$\square$ Secretaria de Atenção à Saúde

$\square$ Secretaria de Gestão do Trabalho e Educação na Saúde

$\square$ Secretaria de Gestão da Saúde

$\square$ Secretaria de Gestão Participativa

$\square$ Secretaria de Ciência, Tecnologia e Insumos Estratégicos

$\square$ Fundação Nacional de Saúde

$\square$ Fundação Osvaldo Cruz

$\square \quad$ ANVISA

$\square$ ANS

$\square$ Hospitais

$\square$ Outro. Especifique:

6. Classifique sua fluência de leitura em outros idiomas:

\begin{tabular}{|l|c|c|c|c|}
\hline \multicolumn{1}{|c|}{ IDIOMAS } & Não Lê & Lê com dificuldade & Razoável & Fluente \\
\hline Espanhol & $\square$ & $\square$ & $\square$ & $\square$ \\
\hline Francês & $\square$ & $\square$ & $\square$ & $\square$ \\
\hline Inglês & $\square$ & $\square$ & $\square$ & $\square$ \\
\hline
\end{tabular}


7. Em que grau você utiliza os meios abaixo para obter informações, artigos ou livros de que precisa.

\begin{tabular}{|l|c|c|c|c|}
\hline \multicolumn{1}{|c|}{ MEIOS } & $\begin{array}{c}\text { Não } \\
\text { Utilizo }\end{array}$ & Utilizo Pouco & $\begin{array}{c}\text { Utilizo } \\
\text { Médio }\end{array}$ & $\begin{array}{c}\text { Utilizo } \\
\text { Bastante }\end{array}$ \\
\hline $\begin{array}{l}\text { Conversa com colegas e } \\
\text { familiares }\end{array}$ & $\square$ & $\square$ & $\square$ & $\square$ \\
\hline Minha biblioteca particular & $\square$ & $\square$ & $\square$ & $\square$ \\
\hline Outras bibliotecas & $\square$ & $\square$ & $\square$ & $\square$ \\
\hline $\begin{array}{l}\text { Biblioteca do Ministério da } \\
\text { Saúde }\end{array}$ & $\square$ & $\square$ & $\square$ & $\square$ \\
\hline Internet & $\square$ & $\square$ & $\square$ & $\square$ \\
\hline Bases de dados & $\square$ & $\square$ & $\square$ & $\square$ \\
\hline Livrarias & $\square$ & $\square$ & $\square$ & $\square$ \\
\hline Televisão, Rádio e Jornal & $\square$ & $\square$ & $\square$ & $\square$ \\
\hline Outros. Especifique:
\end{tabular}

8. Em que grau você utiliza os materiais abaixo para obter a informação de que precisa?

\begin{tabular}{|c|c|c|c|c|}
\hline MATERIAIS & $\begin{array}{c}\text { Não } \\
\text { Utilizo }\end{array}$ & Utilizo Pouco & $\begin{array}{l}\text { Utilizo } \\
\text { Médio }\end{array}$ & $\begin{array}{c}\text { Utilizo } \\
\text { Bastante }\end{array}$ \\
\hline Sites na Internet & $\square$ & $\square$ & $\square$ & $\square$ \\
\hline Livros & $\square$ & $\square$ & $\square$ & $\square$ \\
\hline Dissertações e Teses & $\square$ & $\square$ & $\square$ & $\square$ \\
\hline $\begin{array}{l}\text { Documentos } \\
\text { Manuais }\end{array}$ & $\square$ & $\square$ & $\square$ & $\square$ \\
\hline Revistas e Jornais & $\square$ & $\square$ & $\square$ & $\square$ \\
\hline Periódicos e artigos científicos & $\square$ & $\square$ & $\square$ & $\square$ \\
\hline $\begin{array}{l}\text { Dicionários, enciclopédias e } \\
\text { diretórios }\end{array}$ & $\square$ & $\square$ & $\square$ & $\square$ \\
\hline Atlas e mapas & $\square$ & $\square$ & $\square$ & $\square$ \\
\hline $\begin{array}{l}\text { Fôlderes, } \\
\text { Roms/DVDs }\end{array}$ vídeos, $\quad$ CD- & $\square$ & $\square$ & $\square$ & $\square$ \\
\hline
\end{tabular}

9. Nos últimos 12 meses, qual foi a sua freqüência de utilização da Biblioteca Virtual em Saúde (BVS) e da Biblioteca física do Ministério da Saúde?

\begin{tabular}{|l|c|c|c|c|c|c|}
\hline $\begin{array}{c}\text { Tipo de } \\
\text { Biblioteca }\end{array}$ & $\begin{array}{c}\text { Nunca } \\
\text { utilizei }\end{array}$ & Semanal & Mensal & Bimestral & Semestral & $\begin{array}{c}\text { Não me } \\
\text { recordo }\end{array}$ \\
\hline BVS & $\square$ & $\square$ & $\square$ & $\square$ & $\square$ & $\square$ \\
\hline $\begin{array}{l}\text { Biblioteca } \\
\text { Física }\end{array}$ & $\square$ & $\square$ & $\square$ & $\square$ & $\square$ & $\square$ \\
\hline
\end{tabular}


10. Quais dos serviços da Biblioteca do Ministério da Saúde você utilizou ultimamente?

\begin{tabular}{|l|c|c|c|}
\hline \multicolumn{1}{|c|}{ SERVIÇOS } & $\begin{array}{c}\text { Não conheço } \\
\text { esse serviço }\end{array}$ & $\begin{array}{c}\text { Conheço, mas } \\
\text { nunca utilizei }\end{array}$ & Já utilizei \\
\hline Biblioteca Virtual em Saúde & $\square$ & $\square$ & $\square$ \\
\hline Orientação do balcão de Referência & $\square$ & $\square$ & $\square$ \\
\hline Empréstimo do material & $\square$ & $\square$ & $\square$ \\
\hline Cópia de material de meu interesse & $\square$ & $\square$ & $\square$ \\
\hline Pesquisa bibliográfica em artigos & $\square$ & $\square$ & $\square$ \\
\hline COMUT (solicitação de artigos) & $\square$ & $\square$ & $\square$ \\
\hline Catálogo da Biblioteca & $\square$ & $\square$ & $\square$ \\
\hline Bases de dados da Biblioteca & $\square$ & $\square$ & $\square$ \\
\hline Terminais para acesso à Internet & $\square$ & $\square$ & $\square$ \\
\hline Espaço para leitura e estudo & $\square$ & $\square$ & $\square$ \\
\hline
\end{tabular}

11. Favor avaliar os atributos abaixo relacionados com a Biblioteca do Ministério da Saúde.

\begin{tabular}{|l|c|c|c|c|}
\hline \multicolumn{1}{|c|}{ ATRIBUTOS } & Não sei & Ruim & Bom & Muito Bom \\
\hline Qualidade da coleção & $\square$ & $\square$ & $\square$ & $\square$ \\
\hline Atendimento ao usuário & $\square$ & $\square$ & $\square$ & $\square$ \\
\hline Serviço de empréstimo & $\square$ & $\square$ & $\square$ & $\square$ \\
\hline COMUT (solicitação de artigos) & $\square$ & $\square$ & $\square$ & $\square$ \\
\hline Biblioteca Virtual em Saúde (BVS) & $\square$ & $\square$ & $\square$ & $\square$ \\
\hline Cópias de documentos & $\square$ & $\square$ & $\square$ & $\square$ \\
\hline Equipamentos & $\square$ & $\square$ & $\square$ & $\square$ \\
\hline Ambiente interno & $\square$ & $\square$ & $\square$ & $\square$ \\
\hline Horário de Funcionamento & $\square$ & $\square$ & $\square$ & $\square$ \\
\hline Divulgação & $\square$ & $\square$ & $\square$ & $\square$ \\
\hline
\end{tabular}

12. Você tem interesse em cadastrar-se na Biblioteca do Ministério da Saúde para receber informações, artigos e materiais na sua área de saúde?

$\square$ Não.

$\square$ Sim. Prefiro receber informações em formato eletrônico.

$\square$ Sim. Prefiro receber informações em formato impresso. 